\title{
The co-occurrence of AIDS and homelessness: results from the integration of administrative databases for AIDS surveillance and public shelter utilisation in Philadelphia
}

\author{
D P Culhane, E Gollub, R Kuhn, M Shpaner
}

\begin{abstract}
Study objective-Administrative databases from the City of Philadelphia that track public shelter utilisation $(n=44$ 337) and AIDS case reporting $(n=7749)$ were merged to identify rates and risk factors for co-occurring homelessness and AIDS. Design-Multiple decrement life tables analyses were conducted, and logistic regression analyses used to identify risk factors associated with AIDS among the homeless, and homelessness among people with AIDS.
\end{abstract}

Setting-City of Philadelphia, Pennsylvania, USA.

Main results-People admitted to public shelters had a three year rate of subsequent AIDS diagnosis of 1.8 per 100 person years; nine times the rate for the general population of Philadelphia. Logistic regression results show that substance abuse history $(O R=3.14)$, male gender $(O R=2.05)$, and a history of serious mental disorder $(\mathrm{OR}=$ 1.62) were significantly related to the risk for AIDS diagnosis among shelter users. Among people with AIDS, results show a three year rate of subsequent shelter admission of 6.9 per 100 person years, and a three year rate of prior shelter admission of $9 \%$, three times the three year rate of shelter admission for the general population. Logistic regression results show that intravenous drug user history $(\mathrm{OR}=3.14)$; no private insurance $(O R=2.93)$; black race $(\mathrm{OR}=2.82)$; pulmonary or extrapulmonary TB $(\mathrm{OR}=1.43)$; and pneumocystis pneumonia $(O R=0.56)$ were all related to the risk for shelter admission. Conclusions-Homelessness prevention programmes should target people with HIV risk factors, and HIV prevention programmes should be targeted to homeless persons, as these populations have significant intersection. Reasons and implications for this intersection are discussed. (F Epidemiol Community Health 2001;55:515-520)

Previous studies of the prevalence of homelessness among people with AIDS (PWAs) and the prevalence of HIV/AIDS among people who are homeless have documented that these conditions can frequently co-occur. However, estimates of co-occurrence have varied widely, because of differences in research methods, definitions, locales, and sample selection procedures. This study re-examines this issue by merging administrative databases that register the use of public shelters and the incidence of AIDS cases in a large US city. In so doing, this study demonstrates the feasibility of a highly reliable method for monitoring the cooccurrence of these conditions to inform health care, housing and social service resource allocations.

\section{Literature}

Attempts to measure the rates of co-occurrence of HIV/AIDS and homelessness have been complicated by a range of methodological challenges. Small samples, non-random samples, inconsistent definitions of homelessness, and varying measures of HIV/AIDS, have limited the comparability and generalisability of findings. Nevertheless, this research has raised concerns that homeless people are a distinct at risk group for HIV/AIDS, and that people with HIV/AIDS are at high risk for becoming homeless. The co-occurrence of these conditions is also posited as contributing to the increased rate of active tuberculosis in both the homeless and HIV/AIDS populations.

Estimates of the rate of HIV/AIDS among homeless adults unaccompanied by children (single adults) have ranged from $6 \%$ to $62 \%$. Torres et $a l^{1}$ found that $62 \%$ of a sample of 169 homeless men in New York City were HIV positive; the sample was not random, consisting of persons recommended for voluntary testing because of high risk status or presenting symptoms. Susser et al identified a $19 \%$ rate of HIV infection among homeless shelter users in New York City, based on a sample of 62 men. The sample was not random, consisting of persons in a single shelter for men receiving mental health services. In a related study, Empfield et $a l^{\beta}$ found a $6 \%$ rate of HIV infection among homeless persons admitted to a psychiatric inpatient unit for the "street homeless" in New York City, based on blood samples obtained over two years of admissions. Greer $e t a l^{4}$ found an $11 \%$ seropositivity rate among a sample of homeless persons in Miami, but the sample was also not random, being comprised of people who requested anonymous testing at a health clinic for the homeless. Zolopa et a $\bar{l}$ conducted a population-based, cross sectional study of HIV infection among 916 persons in San Francisco, producing perhaps the most reliable estimate of HIV infection among the homeless adult population, finding an overall rate of HIV 
infection of $10 \%$ among shelter and soup kitchen users.

Similar methodological challenges have confronted efforts to establish the prevalence of homelessness among PWAs. Torres et $a l^{6}$ found that $24 \%$ of a cohort of admissions to a community hospital in New York City with AIDS related disorders (a non-random sample) reported being currently homeless. More commonly, housing needs assessment surveys commissioned by local and state governments or advocacy organisations have been the primary source of data on the housing needs of people with HIV/AIDS, including surveys from Alameda County (CA) $(\mathrm{n}=614)$, Chicago $(\mathrm{n}=828)$, Riverside/San Bernardino $(\mathrm{n}=539)$, Denver ( $\mathrm{n}=581)$, Phoenix $(\mathrm{n}=429)$, Contra Costa County (CA) $(n=90)$, Durham $(n=71)$, Minnesota $(n=97)$ and Philadelphia $(n=785)$. Survey methods and definitions of homelessness have varied, limiting their comparability, and none of the surveys have included random samples. The proportion of respondents reporting to have been homeless since learning of their HIV or AIDS status ranges from $17 \%$ in Durham to $43 \%$ in Alameda County and Chicago. In Philadelphia, a lifetime rate of homelessness of $35 \%$ was found. ${ }^{7}$ The proportion of respondents reporting to be currently homeless comprised $16 \%$ of the total sample in Phoenix, $14 \%$ in Durham, $13 \%$ in Contra Costa County, $10 \%$ in Chicago, $10 \%$ in Alameda County, $5.2 \%$ in Philadelphia, $2 \%$ in Minnesota, $1 \%$ in Denver and 1\% in Riverside/ San Bernadino.

In an alternative approach to survey research methods, researchers have begun to use administrative data to conduct epidemiological studies, including research on the treated prevalence of HIV/AIDS. ${ }^{8}$ This study uses such an approach, through the merging of a public shelter registry and an AIDS surveillance database maintained by the City of Philadelphia. Philadelphia is relatively unique among large cities in the US in having a data registry for public shelter utilisation, having developed the capacity to do so for case management and shelter reimbursement purposes. ${ }^{9}$ Persons who never stay in public shelters are not captured in this database, and so the rate of homelessness among PWAs will be underestimated, as it will for the overall population of Philadelphia. Nevertheless, there is no a priori reason to suspect that ratio measures (risk of public shelter use if HIV infected: risk if not infected) would be affected by undercounting, to the extent that it exists. The shelter and AIDS databases offer the advantages of providing large, highly representative study populations, which include both homeless persons without accompanying children, as well as those with accompanying children. The data are also not dependent on self report for measuring public shelter use or AIDS.

\section{Method}

DATA SOURCES

The City of Philadelphia's Office of Emergency Shelter Services maintains a shelter registry database that records standardised information on persons requesting public shelter (public shelters comprised $84 \%$ of the emergency shelter beds in Philadelphia in 1992) ${ }^{8}$ A separate database records discrete episodes of public shelter use. For this study, the registration file contained unduplicated records for 44337 adults (age 18 and over), both accompanied and unaccompanied by children, who requested shelter from 21 December 1989 to 1 October 1995.

The City of Philadelphia Department of Public Health maintains a database of persons in the City of Philadelphia who have received an AIDS diagnosis, based on a mandated reporting requirement for health care providers. The database began in 1982, and, for this study, was assumed to be current through the diagnosis date of 1 October 1993 (because of a two year reporting lag for some cases). AIDS was defined according to the CDC definition at the time the case was diagnosed; thus, pre-1993 and 1993 case definitions varied. Included in the expanded 1993 case definition was: cd4 count <200; pulmonary TB; recurrent pneumonia; cervical cancer (note: all new conditions require an underlying HIV positive test result to qualify for AIDS). After removing persons under age 18, and persons whose residence was recorded as outside the City of Philadelphia, the file contained records for 7749 persons.

\section{MATCHING PROCEDURES}

The datasets were first merged confidentially, within the AIDS surveillance unit of the Philadelphia Health Department. Using the SAS statistical package (SAS, Inc, Cary, NC), cases were merged by last name, date of birth, sex and first initial. Only matches by all criteria were accepted as valid matches. The merge resulted in 741 positive matches. Identifiers were deleted from the data file, which was then analysed at the University of Pennsylvania.

\section{ANALYSES}

Life table methods were used to construct censored or multiple decrement life tables, modelling the probabilities and rates for having a shelter admission or AIDS diagnosis, in the absence of competing risks. For the analysis of AIDS among a cohort of shelter occupants, anyone who was in shelter at some point in October 1991, was selected, and the risk for future AIDS calculated. The cohort was selected to assure that the opportunity for at least two complete years of AIDS case reporting data were available.

For calculating measures of shelter admissions among people with AIDS diagnoses, we took a cohort of people who were diagnosed during the years 1990-1992. A life table analysis similar to that for the sheltered population was conducted, controlling for right censoring (at 1 October 1995), and counting deaths as censored observations.

Univariate statistics for matched versus unmatched cases in the respective databases were calculated by select characteristics. Among the shelter registry variables, tests of difference were conducted for race, gender, 
Table 1 Rates of AIDS diagnosis among public shelter users, per 100 person years

\begin{tabular}{lllll}
\hline Population & $\begin{array}{l}\text { One year after } \\
\text { shelter admission }\end{array}$ & $\begin{array}{l}\text { Two years after } \\
\text { shelter admission }\end{array}$ & $\begin{array}{l}\text { Three years after } \\
\text { shelter admission }\end{array}$ & Number \\
\hline All & 0.6 & 1.4 & 1.8 & 1829 \\
Women & 0.4 & 1.0 & 1.3 & 690 \\
Men & 0.7 & 1.7 & 2.2 & 1139 \\
Adults with children & 0.4 & 0.6 & 1.1 & 470 \\
Adults without children & 0.7 & 1.7 & 2.1 & 1359 \\
\hline
\end{tabular}

The three year incidence of AIDS for the general population in Philadelphia from 1992-1994 was $0.2 \%$.

Table 2 Rates of public shelter admission among persons with AIDS, per 100 person years

\begin{tabular}{lllll}
\hline Population & $\begin{array}{l}\text { One year after } \\
\text { diagnosis }\end{array}$ & $\begin{array}{l}\text { Two years after } \\
\text { diagnosis }\end{array}$ & $\begin{array}{l}\text { Three years after } \\
\text { diagnosis }\end{array}$ & $\begin{array}{l}\text { Three years before } \\
\text { diagnosis }\end{array}$ \\
\hline All PWAs & 3.9 & 5.7 & 7.4 & 10.3 \\
\hline
\end{tabular}

The three year rate of shelter admission for the general population of Philadelphia was $2.7 \%$, from 1990-1992.
AIDS case (up to two years). This figure is nine times the three year incidence for the general population between 1992 and $1994(0.2 \%) .{ }^{12}$ The three year rate for adults unaccompanied by children ( 2.0 per 100 person years) is almost twice the rate for adults accompanied by children (1.1 per 100 person years); this higher rate subgroup comprised most $(73 \%)$ of the people with AIDS using public shelters. The three year rate for men (2.2 per 100 person years) is almost twice that for women (1.3 per 100 person years); still, women comprised proportionately more of the sheltered population with AIDS $(26 \%)$ than the general Philadelphia population with AIDS (15\%). Among the shelter cohort, $2.5 \%$ ever received an AIDS diagnosis, including $0.2 \%$ who were diagnosed more than three years after shelter admission and $0.7 \%$ who were diagnosed any time before shelter admission. abuse problem, presence or treatment history of a serious mental illness or other mental disorder, and pattern of shelter use (transitional, episodic and chronic). The behavioural health information combines intake data from the shelter registry (interviewer determined, or self report) with that from nine years of Medicaid, Medicare, state hospital, community mental health programme and case management data. ${ }^{10}$ Thus, an indicator flag was created if the person ever received treatment in the public health system or paid for by public insurance, or if the person self reported such a condition or the interviewer at intake upon shelter admission determined that such a condition was present. The behavioural health variables thus probably overstate the rate of behavioural health problems, accepting any indication as valid, and not requiring verification by multiple sources. The variables for pattern of shelter use were developed based on a cluster analysis of shelter episodes and days. ${ }^{11}$ The variables examined from the AIDS case registry included gender, AIDS risk background, race, age, and selected opportunistic illnesses (pneumocystis pneumonia, (PCP) active TB, recurrent pneumonia). The AIDS case registry information is obtained from mandated physician reporting, with data completeness checked at the time of the report, and with periodic audits conducted, along with follow up requests, to complete missing information. Periodic review of hospital records identifies potentially unreported cases, and physicians are subsequently asked to provide complete information. Significant variables $(\mathrm{p}<0.10)$ were entered into a logistic regression model for each database using backwards elimination.

\section{Results}

AIDS DIAGNOSIS AMONG PUBLIC SHELTER USERS

Table 1 shows the life table results of the incidence of AIDS in a shelter cohort. An incidence of AIDS of 0.6 per 100 person years one year after shelter admission was found, increasing to 1.4 per 100 person years after two years and 1.8 per 100 person years after three years from shelter admission. This last estimate, if anything, is believed to be an undercount because of the lag time to be allowed between diagnosis and report of an

\section{PUBLIC SHELTER ADMISSIONS AMONG PERSONS} WITH AIDS

As shown in table 2, the rate of public shelter admission one year after AIDS diagnosis was found to be 3.9 per 100 person years, increasing to 5.7 per 100 person years after two years, and 7.4 per 100 person years after three years. The most at risk period for shelter admission was during the first six months after an AIDS diagnosis. By five years after diagnosis, 10.9\% of persons with AIDS had a shelter admission. Among persons with AIDS diagnosed between January 1993 and September 1993 (n=967), $10.3 \%$ stayed in a shelter in the three years before their diagnosis. This compares with a rate of shelter admission in the previous three years of $2.7 \%$ for the general population of Philadelphia from 1990 through $1992 .^{8}$

SHELTERED POPULATION CHARACTERISTICS

ASSOCIATED WITH AN AIDS DIAGNOSIS

Univariate analyses of variables associated with AIDS among shelter users suggested associations with the following: male gender $(\mathrm{OR}=$ 2.39), indicated substance abuse problem or treatment history $(\mathrm{OR}=3.70)$; ever a diagnosis of serious mental illness $(\mathrm{OR}=2.21)$; and episodic pattern of shelter use $(\mathrm{OR}=2.42)$. Episodic shelter users (people with an average of 3.8 shelter admissions and an average stay of 75 days over a two year period), are more likely to be black $(\mathrm{OR}=2.30)$ than the other clusters, more likely to be Hispanic (OR = 1.77), more likely to have a history of substance abuse (OR mentally ill $(\mathrm{OR}=1.35) \cdot{ }^{11}$ When the significant variables were entered into a logistic model (see table 3, only substance abuse $(\mathrm{OR}=3.20$; $95 \%$ CI 2.8, 3.8); male gender $(\mathrm{OR}=2.08$; $95 \%$ CI $1.7,2.4)$; and a history of serious mental disorder $(\mathrm{OR}=1.63 ; 95 \%$ CI $1.3,2.0)$ were significant $(p<0.01)$. Episodic shelter use was not significant (OR 1.26, $\mathrm{p}=0.10$ ). It was not possible to control for sexual risk background in these analyses because that information was not collected; therefore it is unclear whether the raised risk for men would also hold for those with a heterosexual risk background. = 2.36), and more likely to be ever seriously 
Table 3 Sheltered population characteristics associated with an AIDS diagnosis: logistic regression results

\begin{tabular}{llllllll}
\hline Variable & DF & $\begin{array}{l}\text { Parameter } \\
\text { estimate }\end{array}$ & Standard error & Wald $\chi^{2}$ & p Value & $\begin{array}{l}\text { Standardised } \\
\text { estimate }\end{array}$ & Odds ratio \\
\hline Intercept & 1 & -4.9826 & 0.0787 & 4004.90 & 0.000 & & $2.050^{\star}$ \\
Male & 1 & 0.7181 & 0.0860 & 69.64 & 0.000 & 0.197 & 1.258 \\
Episodic & 1 & 0.2296 & 0.1403 & 2.68 & 0.102 & 0.024 & $3.142^{\star}$ \\
Substance abuse & 1 & 1.1449 & 0.0775 & 218.38 & 0.000 & 0.2567 & $1.618^{\star}$ \\
Severe mental illness & 1 & 0.4810 & 0.1122 & 18.365 & 0.000 & 0.066 & \\
\hline
\end{tabular}

^Significant at $<0.05$.

CHARACTERISTICS OF PWAS ASSOCIATED WITH SHELTER ADMISSION

Univariate analyses demonstrated that shelter admission among persons with AIDS were associated with injection drug use history (OR $=4.75)$; black race $(\mathrm{OR}=4.57)$; public or no health insurance $(\mathrm{OR}=4.48)$; female gender $(\mathrm{OR}=2.26)$; recurrent pneumonia $(\mathrm{OR}=$ 2.25); tuberculosis (pulmonary $\mathrm{OR}=2.27$; any TB OR 2.12); PCP (OR= 0.51); Hispanic race $(\mathrm{OR}=0.35)$; and Kaposi's sacrcoma $(\mathrm{OR}=0.20)$. Significant heterogeneity was noted by gender, thus, the significant univariate variables were entered into separate logistic models by gender. The final model for men (see table 4 ) included only black race $(\mathrm{OR}=$ 2.82); Hispanic race ( $\mathrm{OR}=0.38)$; intravenous drug use history (OR = 3.14); no private insurance $(\mathrm{OR}=2.93)$, any $\mathrm{TB}(\mathrm{OR}=1.43), \mathrm{PCP}$ $(\mathrm{OR}=0.56)$, and Kaposi's sarcoma $(\mathrm{OR}=0.34)$. Hispanic PWAs had a lower rate of shelter admissions than black PWAs (3.3\% versus $12.2 \%$ ever); although this rate was still greater than for whites $(2.6 \%)$. The final model for women (see table 5) included black race $(\mathrm{OR}=2.96)$, intravenous drug use $(\mathrm{OR}=1.84)$, and no private insurance $(\mathrm{OR}=1.60)$.

\section{Discussion}

This study confirms in a large study population that homelessness and AIDS frequently cooccur. In Philadelphia, homeless shelter users have nine times the risk of having AIDS as the general population. And PWAs were observed to be three times as likely to have been homeless than the general population. Among shelter users, behavioural health problems, including both substance abuse and serious mental disorders, are associated with greater risk for AIDS, as is male gender. Among male PWAs, intravenous drug use history, black race, and having public or no health insurance are all positively related to risk for shelter admission, as is having any tuberculosis, while being Hispanic and having PCP are negatively related to shelter admission. This latter finding may be because of the reduced probability of shelter admission that results from the hospitalisation associated with PCP or severe AIDS illness. Among female PWAs, black race, intravenous drug use history and having public or no health insurance are also positively related to shelter admission. Further research is needed to determine the sequencing of shelter admission and infectious disease among PWAs.

Among PWAs, the increased risk for shelter admission among persons of black race may be related to the heightened risk for shelter admission among persons of black race more generally, who account for $90 \%$ of the people in Philadelphia shelters, while comprising only $40 \%$ of the city's population $(\mathrm{OR}=2.36) .{ }^{9}$ This differential in risk may indicate continuing discrimination in housing against persons of black race, more limited income to afford market rents, the effects of residential segregation on housing stability, and differential access to resources for managing housing emergencies. The decreased rate of shelter admission among Hispanic persons as compared with black people (still increased compared with white people) is difficult to interpret. This finding is consistent with the lower risk for shelter admission among Hispanic persons generally in Philadelphia, ${ }^{9}$ and may be related

Table 4 Characteristics of male PWAs associated with public shelter admission: logistic regression results

\begin{tabular}{llllllll}
\hline Variable & DF & $\begin{array}{l}\text { Parameter } \\
\text { estimate }\end{array}$ & Standard error & Wald $\chi^{2}$ & p Value & $\begin{array}{l}\text { Standardised } \\
\text { estimate }\end{array}$ & $\begin{array}{l}\text { Odds } \\
\text { ratio }\end{array}$ \\
\hline Intercept & 1 & -4.2762 & 0.2408 & 315.42 & 0.000 & & $2.815^{\star}$ \\
Black & 1 & 1.0350 & 0.1617 & 40.96 & 0.000 & 0.281 & $0.381^{\star}$ \\
Hispanic & 1 & -0.9637 & 0.3013 & 10.23 & 0.001 & -0.149 & $3.136^{\star}$ \\
IV drug & 1 & 1.1430 & 0.1409 & 65.85 & 0.000 & 0.301 & 0.774 \\
Homosexual/bisexual & 1 & -0.2558 & 0.1342 & 3.63 & 0.057 & -0.0667 & $2.931^{\star}$ \\
No private insurance & 1 & 1.0753 & 0.1671 & 41.42 & 0.000 & 0.281 & $1.427^{\star}$ \\
Any TB & 1 & 0.3558 & 0.1702 & 4.37 & 0.037 & 0.045 & $0.556^{\star}$ \\
Pneumocystis pneumonia & 1 & -0.5867 & 0.1338 & 19.23 & 0.000 & -0.147 & $0.338^{\star}$ \\
Kaposi's sarcoma & 1 & -1.0841 & 0.3690 & 8.63 & 0.003 & -0.167 & $0^{\star}$
\end{tabular}

$\star$ Significant at $<0.05$.

Table 5 Characteristics of female PWAs associated with public shelter admission: logistic regression results

\begin{tabular}{llllllll}
\hline Variable & DF & $\begin{array}{l}\text { Parameter } \\
\text { estimate }\end{array}$ & Standard error & Wald $\chi^{2}$ & $p$ Value & $\begin{array}{l}\text { Standardised } \\
\text { estimate }\end{array}$ & Odds ratio \\
\hline Intercept & 1 & -3.1785 & 0.3431 & 85.83 & 0.000 & - & - \\
Black & 1 & 1.0861 & 0.2310 & 22.11 & 0.000 & 0.272 & $2.963^{\star}$ \\
IV drug & 1 & 0.6105 & 0.1840 & 11.01 & 0.001 & 0.167 & $1.841^{\star}$ \\
No private insurance & 1 & 0.4669 & 0.2800 & 2.78 & 0.095 & 0.092 & 1.595
\end{tabular}

$\star$ Significant at $<0.05$ 
to a comparatively greater use of family and friends for housing crises among Hispanic persons with HIV/AIDS. ${ }^{7}$

The increased risk for shelter admission among intravenous drug users with AIDS suggests that drug use increases housing instability, possibly through its association with family conflict, employment problems, and health problems. Greater access to residential treatment for substance abuse among PWAs may help to reduce their risk for shelter admission, and was reported as a desired option among many substance abusing people with HIV/AIDS in a recent consumer survey in Philadelphia. ${ }^{7}$ The association of IVDU with shelter admission also suggests that needle exchange programmes that target homeless persons may help to reduce the risk for HIV transmission in this high risk population.

The positive association between having no insurance or receiving public insurance and being admitted to a shelter among PWAs is probably a proxy for low income. No other income variables are available in the AIDS registry. However, it is also possible that having public or no health insurance increases the risk for shelter admission as it may contribute to reduced access to necessary health services and supports.

The findings that tuberculosis and recurrent pneumonia among PWAs are positively related to public shelter admission highlights both the potential health effects of homelessness for PWAs, and the health risk that shelter residence among PWAs may pose for other shelter users. The increasing prevalence of tuberculosis has been argued as related to the presence of more immunocomprised persons in crowded, congregate shelters, which frequently have substandard health conditions. This study lends weight to the increasingly common concern about the spread of TB in shelters, and suggests that improved housing standards for PWAs (as well as for people who are homeless), more widespread testing and test referral, and more effective treatment for TB among shelter users may be important to reverse this trend.

This study also confirms that homeless people (or shelter users) represent a very high risk subpopulation for developing AIDS. This result may be attributable in part to the role of housing instability in contributing to high risk behaviours (that is, trading sex and drugs for housing), and the greater exposure to drug activity by residence in substandard housing and poorer neighbourhoods. Substance abuse and mental health problems also contribute to housing instability and to a higher probability of engaging in high risk behaviours. Thus, improved access to residential treatment for substance abuse for people who are homeless or at risk of homelessness could reduce the risk for both HIV transmission and homelessness. Similarly, by expanding housing opportunities for people with serious mental disorders, who have a disproportionately high rate of shelter admission $(\mathrm{OR}=3.0),{ }^{13}$ this may reduce their risk for HIV infection, as may the development
KEY POINTS

- AIDS and homelessness co-occur at very high rates: AIDS is nine times more prevalent among the homeless in Philadelphia than in the general population, and homelessness is three times more prevalent among people with AIDS than the general population.

- Among the homeless, being male, having a substance abuse problem and having a severe mental disorder, were all significant risk factors for AIDS.

- Among people with AIDS, being an intravenous drug user, of black race, lacking private health insurance, and having pneumonia, were all significant risk factors for homelessness.

- To reduce the risk for HIV transmission and homelessness, residential treatment for substance abuse is needed, particularly for poorly insured or uninsured men of black race, and for people with severe mental disorders.

and targeting of more appropriate HIV prevention programming for such persons. Finally, improved access to affordable housing generally could contribute to a reduction in high risk behaviours.

Because this study includes the known populations of shelter users and PWAs, it provides a unique opportunity to examine the issue of co-occurring homelessness and AIDS. Future research should consider the potential benefits of this approach for monitoring the co-occurrence of these conditions over time and in other locations, as other cities develop computerised archives on shelter use.

Limitations to this study include the following. The October 1991 study period for selecting homeless persons for later AIDS reporting, may be affected by seasonality in shelter admissions. Shelter admissions peak in the winter months (December to February), suggesting that some street homeless may have been underrepresented in October, relative to the winter months. This could have contributed to a modest underestimation of the rate of AIDS in the homeless population, as compared with a later winter period; likewise, the October sample may contribute to a modest overestimation as compared with a summer period, when shelter use is lowest. Use of administrative data for epidemiological analyses, while affording more subjects and greater statistical power, also have limitations. Administrative datasets are not generally designed for research purposes, and are not regularly audited for their reliability with respect to the variables under study; therefore, administrative data may have errors. However, previous comparisons of administrative health services data and clinical records show a high degree of correspondence. ${ }^{14}$ Nevertheless, administrative data record only treated or indicated observations, and only for treated individuals, and thus cannot be generalised to untreated cases. 
The research summarised in this paper was performed under contract with the City of Philadelphia Office of Mental Health. Conflicts of interest: none.

1 Torres RA, Sridhar M, Altholz J, et al. Human immunodeficiency virus infection among homeless men in a New deficiency virus infection among homeless men in a

2 Susser E, Valencia E, Conover S. Prevalence of HIV infection among psychiatric patients in a New York City men's

3 Empfield M, Cournos F, Meyer I, et al. HIV seroprevalence among homeless patients admitted to a psychiatric inpatient unit. Am f Psychiatry 1993;150:47-52.

4 Greer P, Dickinson G, Parra F, et al. HIV seropositivity in a clinic for the homeless. The Fifth Annual International Conference on AIDS. June 4-9, 1989.

5 Zolopa A, Vranizan K, Meakin R, et al. Tuberculosis and HIV infection in the homeless population of San Francisco, CA. The Eighth Annual International Conference on AIDS, July 19-24, 1992.

6 Torres RA, Mani S, Martin M, et al. Homelessness among hospitalized patients with AIDS-related complex in New York City. The Fifth International Conference on AIDS, June 4-9, 1989 .

7 Acquaviva K, Culhane DP. AIDS housing needs assessment: results from a consumer survey. City of Philadelphia: Office of results from a consumer survey. City of Philadelph.
Housing and Community Development, 1996.
8 Walkup, J, Crystal, S, Sambaboorthi, U. Schizophrenia and major affective disorder among Medicaid recipients with HIV/AIDS in New Jersey. Am f Public Health 1999:89: 1101-3.

9 Culhane DP, Dejowski E, Ibanez J, et al. Public shelter admission rates in Philadelphia and New York City: The implications of turnover for sheltered population counts. Housing Policy Debate 1994;5:107-40.

10 Culhane DP, Averyt J, Hadley TR. The treated prevalence of behavioral health disorders among adults admitted to the Philadelphia shelter system: Results from the integration of longitudinal data on behavioral health and shelter utilization. Rockville, MD: US DHHS, SAMHSA, Center for Mental Health Services (in press)

11 Kuhn R, Culhane DP. Applying cluster analysis to test a typology of homelessness by pattern of public shelter utilization: results from the analysis of administrative data. Am f Community Psychol 1998;17:23-43.

12 AIDS Activities Coordinating Office. Quarterly report. Philadelphia. Philadelphia Department of Health, 1994.

13 Culhane DP, Averyt, J, Hadley TR. The rate of public shelter admission among Medicaid-reimbursed users of behavioral health services. Psychiatr Serv 1997;48:390-2.

14 Lurie N, Popkin M, Dysken M, et al. Accuracy of diagnoses of schizophrenia in Medicaid Claims. Hospital and Community Psychiatry 1992;43:69-71. 